\title{
Contribución de la educación popular al pensamiento descolonizador: prácticas pedagógicas universitarias en Cuba y Brasil
}

\author{
Contribuição da Educação Popular para o pensamento \\ descolonizador: Práticas pedagógicas \\ universitárias em Cuba e no Brasil
}

\section{Contribution of Popular Education to decolonizing thinking: University pedagogical practices in Cuba and Brazil}

\author{
MARÍA VICTORIA GONZÁLEZ PEÑA (iD ${ }^{a}$ \\ LEÔNCIO JOSÉ GOMES SOARES (iD ${ }^{\mathrm{b}}$
}

\section{Resumen}

La educación popular y su contribución a los procesos universitarios en la actualidad, se convierten en necesidad ante la sistematización de prácticas pedagógicas cada vez menos inclusivas y marcadas por diferentes formas de opresión. De ahí que el objetivo del artículo, es argumentar la contribución de la Educación Popular, (EP) como perspectiva teórico-metodológica, para reflexionar y revertir estas manifestaciones en el contexto de la educación superior del siglo XXI. El análisis bibliográfico ha permitido la obtención de antecedentes históricos, dimensiones y contribuciones de la EP a la teoría pedagógica que,

a Universidad de Camaguey, Camaguey, Provincia de Camaguey, Cuba. Doctora en Pedagogía, e-mail: mariavictoriagonzalezpena@gmail.com

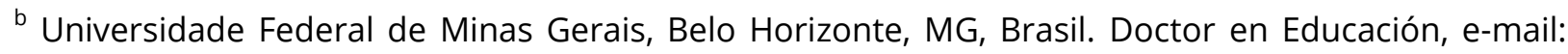
leonciosoares@uol.com.br 
unida al pensamiento de Freire y sus seguidores, abordan de forma contrahegemónica y descolonizadora el tratamiento a estas prácticas. Por otra parte, la etnografía educativa posibilita explicar ejemplos de prácticas emancipadoras universitarias en cursos de postgraduación en universidades brasilera y cubana. Los resultados teórico-prácticos contribuyen a develar en el contexto educativo universitario relaciones de poder y comportamientos que reproducen de manera natural el pensamiento colonizador. Las conclusiones indican cuánto es posible avanzar en el diálogo entre los saberes académicos y populares y, se advierte la necesidad de continuar perfeccionando los procesos universitarios en aras de lograr la formación de sujetos cada vez más comprometidos con la descolonización educativa y la transformación social.

Palabras claves: Educación popular. Universidad. Emancipación. Pedagogía. Descolonización.

\section{Resumo}

A educação popular e sua contribuição aos processos universitários hoje tornam-se uma necessidade, diante da sistematização de práticas pedagógicas cada vez menos inclusivas marcadas por diferentes formas de opressão. Por isso, o objetivo do artigo é argumentar a contribuição da Educação Popular como uma perspectiva teórico-metodológica, para refletir e reverter essas manifestações no contexto da educação superior do século XXI. A análise bibliográfica permitiu a obtenção de fundo históricos, dimensões e contribuições do EP à teoria pedagógica de que, juntamente com o pensamento de Freire e seus seguidores, abordam de forma contragemônica e descolonizante o tratamento desses práticas. Por outro lado, a etnografia educacional possibilita explicar exemplos de práticas emancipatórias universitárias em cursos de pós-graduação em universidades brasileira e cubana. Os resultados teóricopráticos contribuem para a revelação no contexto educacional universitário de relações e comportamentos que naturalmente reproduzem o pensamento colonizador. Os achados indicam até onde o progresso é possível no diálogo entre o conhecimento acadêmico e popular $e$, vemos a necessidade de continuar a refinar os processos universitários para alcançar a formação de assuntos cada vez mais comprometidos com descolonização educacional e transformação social.

Palavras-chave: Educação popular. Universidade. Emancipação. Pedagogia. Descolonização.

\section{Abstract}

Popular education and its contribution to university processes today become a necessity, in the face of the systematization of increasingly less inclusive pedagogical practices marked by different forms of oppression. Hence the aim of the article is to argue the contribution of 
Popular Education (EP) as a theoretical-methodological perspective, to reflect and reverse these manifestations in the context of 21st century higher education. Bibliographic analysis has allowed the obtaining of historical background, dimensions and contributions of the EP to the pedagogical theory that, together with the thought of Freire and his followers, treat in a counterhegemonic and decolonizing way the treatment of these Practices. On the other hand, educational ethnography makes it possible to explain examples of university emancipatory practices in postgraduate courses at Brazilian and Cuban universities. Theoretical-practical results contribute to revealing in the university educational context power relations and behaviors that naturally reproduce colonizing thinking. The findings indicate how far progress is possible in the dialogue between academic and popular knowledge and, we see the need to continue to refine university processes in order to achieve the formation of subjects increasingly committed to educational decolonization and social transformation.

Keywords: Popular education. University. Emancipation. Pedagogy. Decolonization.

\section{Introducción}

En el siglo XXI el campo de la Educación Popular (EP) “continúa siendo un universo abierto y en construcción y, es necesario continuar reflexionando sobre el saber pedagógico que respalda esta propuesta educativa”. (TORRES, 2016, p.56) Ella se constituye en un campo de estudio, que aunque no se aplica de manera homogénea, ni posee un cuerpo de categorías sistematizadas en todos sus extremos, en América Latina y otros contextos se vive y se transforma críticamente en sí misma, en función de los desafíos de la transformación social de cada momento histórico, lo cual advierte la necesidad de profundizar en ella al ser considerada como "un paradigma emancipador" como dijera Jara (2018, p. 5)

Son varios los autores que han abordado y abordan la EP como campo de investigación, reflexión, práctica pedagógica y profundización necesaria. (BETTO, 2014, 2018); (BRANDAO, 2012, 2013); (FREIRE, 1968, 1970, 1986, 1997, 2013); (JARA, 2005,

2018); (MEJÍAS, 2011, 2015); (NÚÑEZ, 2013); (PONTUAL, 2006); (SOUSA SANTOS, 2008, 2010); (TORRES, 2016). 
Aunque estos investigadores realizan estudios y experiencias desde diferentes ámbitos, tienen como punto en común que el legado de la EP constituye una concepción político-pedagógica que contribuye a la construcción y concientización de los sujetos para develar su condición de opresión y descolonización de la realidad que viven y, por tanto es una vía para gestionar procesos pedagógicos que reinventen la democracia.

$\mathrm{Al}$ respecto, es importante retomar, en síntesis, la caracterización sobre el panorama socio económico que hoy se vive en Latinoamérica:

El nivel de exclusión y miseria causado por el neoliberalismo exige medidas urgentes que no escapan al mero asistencialismo. Sin embargo, tal asistencialismo se restringe al acceso a beneficios personales (bono financiero, escuela, atención médica, crédito facilitado, dotación de productos básicos, etc.), sin que haya complementación con procesos pedagógicos de formación y organización políticas. Se dan beneficios sin suscitar esperanza. Se promueve el acceso al consumo, sin propiciar el surgimiento de nuevos protagonistas sociales y políticos. Se valora al consumidor y no al ciudadano. El capitalismo post neoliberal introduce "valores" - como la competitividad y la mercantilización de todos los aspectos de la vida y de la naturaleza, reforzando el individualismo y el conservadurismo. (BETTO, 2018, p. 8, traducción CEAAL)

A este contexto y esta realidad la escuela no se excluye e infelizmente reproduce formas soioculturales de comportamientos y valores que no siempre contribuyen a superar prácticas educativas colonizadoras.

En tal sentido, la trascendencia social que tiene la universidad como institución que debe llegar al pueblo y nutrirse de él para poder perfeccionar los procesos formativos que en ella acontecen, demanda la sistematización creciente de procesos democráticos que el siglo XXI impone. Resulta impostergable para el logro de este propósito tomar en cuenta los principios, dimensiones y valores que promueve la EP que como propuesta políticopedagógica hace parte de los desafíos y favorece la formación de sujetos políticos, críticos, activos y comprometidos con su realidad social.

El legado pedagógico de Freire, en torno a la Pedagogía crítica y la EP, ha ejercido influencia en numerosos educadores, movimientos y organizaciones sociales que lo convierten en líder de la educación emancipadora y la transformación social, no sólo en Latinoamérica sino también a nivel mundial. 
El análisis bibliográfico realizado permitió presentar un breve recorrido histórico sobre la EP en Latinoamérica, reflexionar sobre enfoques y tendencias que son inherentes a esta concepción político-pedagógica y argumentar desde la Pedagogía su contribución a procesos universitarios. Por su parte, la etnografía educativa posibilita la ejemplificación de prácticas pedagógicas universitarias emancipadoras, a través de cursos de postgraduación, en la Universidad Federal de Minas Gerais, Brasil y la Universidad de Camagüey en Cuba. De manera que, la universidad del siglo XXI sea portadora de este legado de la EP para contribuir a la formación de sujetos conscientes de transformar su realidad social y democratizar cada vez más los procesos formativos de los cuales participan.

\section{Breve recorrido histórico de la Educación Popular en Latinoamérica}

A finales del siglo XVIII y primera mitad del siglo XIX, durante la organización de las luchas independentistas, los debates del liberalismo pedagógico encuentran correspondencia con los nuevos paradigmas educativos considerados apropiados a la coyuntura de emancipación colonial. (ROMERO, 2013). En tal sentido, dos referentes resultan significativos en el inicio de las ideas de la educación popular. Las del venezolano Simón Rodríguez (1771-1854) y el apóstol cubano José Martí (1853-1895).

El primero considera que "la educación de las masas populares es una condición y una garantía para la democratización de las jóvenes repúblicas hispanoamericanas". (TORRES, 2016, p.24). Esta educación ha de constituir una herramienta para formar

ciudadanos latinoamericanos y no europeos; de ahí su frase célebre o inventamos o erramos. Su pensamiento encuentra en la educación la clave para que se asuma un modelo educativo que ha de crear una masa ciudadana que luche por la emancipación del modelo colonial. Su perspectiva, rompe con el discurso pedagógico imperante y propone la necesidad de una pedagogía que responda a las demandas de la realidad latinoamericana. (ROMERO, 2013). 
El segundo reconoce que no hay buena educación sin instrucción y que: “[...] el pueblo más feliz es el que tenga mejor educados a sus hijos, en la instrucción del pensamiento, y en la dirección de los sentimientos" (VALDÉS, 2007, p. 145). Abogaba además por la necesaria relación entre la educación y los tiempos que vive cada sociedad, “Al mundo nuevo corresponde la escuela nueva [...]” (VALDÉS, 2007, p.147). También destaca que en el acto pedagógico, las relaciones entre el educador y el educando deben estar impregnadas de amor y, defiende la necesidad del diálogo en dicho acto, para ello, la importancia de tener en cuenta las experiencias de los educandos.

Es recogido también en el diccionario del pensamiento martiano que:

Educación popular no quiere decir exclusivamente educación de la clase pobre; sino que todas las clases de la nación, que es lo mismo que el pueblo, sean bien educadas. Así como no hay ninguna razón para que el rico se eduque, y el pobre no, ¿qué razón hay para que se eduque el pobre, y no el rico? Todos son iguales. (VALDÉS, 2007, p.145).

Cada uno en su tiempo aporta ideas avanzadas al pensamiento pedagógico existente, enfatizan en la educación para todos y todas y, revelan a la educación como proceso de formación de la conciencia histórica, vía para la acción emancipadora y de creación de un pensamiento descolonizador que contribuya a transformar la realidad social imperante.

En la década de 1920, con la influencia del movimiento reformista de Córdoba en Argentina, surgen varias universidades populares en países de la región latinoamericana y caribeña, entre ellos Perú, Cuba, San Salvador, Chile, que tuvieron en común constituir espacios en los cuales se intentó una relación entre los intelectuales y las masas populares, mediante relaciones educativas democráticas que llegaron a convertirse en algunos casos, en una educación autogestionaria. En esta década se desarrolló también una vertiente pedagógica popular, democrática y nacionalista, pero no marxista, entre las que se destaca la extraordinaria experiencia de Augusto César Sandino en Nicaragua. Asimismo, el político y pedagogo peruano José Carlos Mariátegui, quien aporta desde su obra y acción a la construcción de una pedagogía popular, nacional y latinoamericana, desde un marco teóricomarxista. Otras expresiones de educación popular surgen también en la década del 30 del 
siglo XX en Bolivia, interesados en aplicar modelos educativos basados en principios socialistas, poner la escuela al servicio del pueblo y en rescatar la tradición de la comunidad indígena. (MEJÍAS; AWAD, 2007)

En el siglo XX entre los años del 1940 y 1950 “" ... los movimientos populares de Argentina, Perú, México y Colombia vieron en la educación y la cultura un espacio para su desenvolvimiento y trataron de impregnar a la educación de un carácter nacionalista y democrático". (ROMERO, 2013, p.235)

Los años de 1960, estuvieron caracterizados por varios acontecimientos históricos, políticos y sociales y con la presencia de fuertes dictaduras militares en Uruguay, Argentina, Brasil entre otros, se levantan varios movimientos sociales que pretenden transformar las condiciones de opresión en las que estaban inmersos la mayoría de los países de América Latina y estimularon a pensar en un modelo político, social, educativo, transformador. Por lo que resurge la idea de construir un proyecto coherente con las necesidades de cambio, al que se le llamó educación popular. (MEJÍAS; AWAD, 2007)

En esta misma década la EP como concepto, alcanza su sistematización teórica primigenia en las entrañas del pueblo latinoamericano, especialmente en Brasil, con los estudios y la práctica pedagógica del eminente pedagogo brasileño Paulo Freire (1921-1997), el cual es considerado el precursor de la educación popular latinoamericana, al considerarla como pedagogía de los oprimidos. En su obra se aprecia una clara influencia del humanismo cristiano, de la Psicología, la Pedagogía, la Sociología de la educación y de corrientes filosóficas como la Teología de la liberación y el marxismo, en particular del pensamiento del filósofo italiano Antonio Gramsci.

Además, la EP en Brasil bajo el protagonismo de Freire, desde sus inicios también es considerada como un Movimiento de Cultura Popular en el que se busca articular arte y ciencia y pedagogía y política. Parte importante de experiencias pedagógicas de los trabajos de cultura popular centraron su atención en la Alfabetización de Adultos. (BRANDAO, 2013).

De manera que desde la década del 1960 hasta la actualidad, la educación popular se ha convertido en y un movimiento ético, político-pedagógico y cultural con fuerte presencia en América Latina, en el que significa a Freire como su principal protagonista y, 
fundamentalmente se pondera en su obra escrita y su actividad práctica el vínculo entre la educación y la cultura en el que considera a la primera como el camino viable para la liberación de los pueblos. A través de la trayectoria de su obra convoca a profundizar en lo político a través de la educación y, ratifica que la educación por sí misma no cambia el mundo, pero sin ella es imposible hacerlo. (FREIRE, 1986).

\section{Enfoques y tendencias en torno a la educación popular}

La EP ha sido denominada indistintamente como concepción educacional, metodología, educación liberadora, nuevo paradigma educacional, entre otros. Al respecto, se analizan algunas de estas denominaciones, que constituyen referentes de esencia en el presente trabajo.

A partir de la crítica a la educación bancaria, el pensamiento pedagógico de Paulo Freire apuesta a una educación con un enfoque liberador que se propone la concientización de la situación de opresión de los sectores populares y por tanto a la construcción de un pensamiento descolonizador, como momento necesario para su transformación. (ALEJANDRO et al., 2012).

En la propuesta de Freire de la Educación como práctica de libertad, centra su interés en la integración del individuo con su situación. Plantea un cambio profundo de las relaciones entre el educador y el educando y explicita la necesidad de que la educación debe servir para que los educadores y educandos aprendan a leer la realidad para escribir su historia y sean protagonistas de esta. (TORRES, 2016).

La educación popular liberadora presupone saber usar el poder desde otros patrones y modelos que no reproduzcan las posiciones de dominado y dominante, de objeto y sujeto. Se trata de apostar por transformarlo en un poder que se comparte, que diluye las jerarquías y convida a la horizontalidad, que promueve participación en el proceso de construcción colectiva de propuestas. (ALEJANDRO et al., 2012). 
En la búsqueda conceptual de la EP como concepción educacional, confluyen diversas contribuciones y corrientes teóricas. Está apoyada en una filosofía de la praxis educacional entendida como un proceso político-pedagógico centrado en el ser humano como sujeto histórico transformador, que se constituye socialmente en las relaciones con los otros seres humanos y con el mundo. Además se opone, critica la cultura de la dominación y promueve prácticas emancipadoras en las relaciones de poder en cualquier espacio.

Por eso, esta concepción educacional está basada en principios políticos que apuntan a la construcción de relaciones de poder equitativas y justas en los diferentes ámbitos de la vida y en una pedagogía crítica y creadora, que busca el desarrollo pleno de todas las capacidades humanas: cognitivas, psicomotoras, emocionales, intelectuales y valorativas. (JARA, 2005).

Al decir del investigador y educador popular João Francisco de Souza (2005), no se puede simplemente, extrapolar una concepción y una práctica pedagógica de un tiempo o de un contexto a otro. La educación como una actividad cultural es un instrumento para el desarrollo de la cultura, capaz de contribuir con la democratización fundamental de la sociedad, de la propia cultura y con el enriquecimiento cultural de sus diferentes sujetos, especialmente sujetos populares. En esa perspectiva, se reafirma, que el contenido de los procesos educativos es la construcción de la comprensión, de la interpretación, de la explicación de la realidad natural y cultural.

También, "la EP se asume como metodología participativa que transciende el uso de las técnicas para gestionar de forma permanente los procesos educativos y sociales e incorporar relaciones democráticas que caractericen a la nueva sociedad". (TORRES, 2016, p.51) Sin embargo, se mantiene un debate con distintas experiencias existentes en el campo de la educación popular, y con ciertas concepciones de formación política de corrientes que la estigmatizan, la caricaturizan, y que incluso, desde un discurso que se presenta como revolucionario, tienden a reproducir viejos y nuevos dogmatismos. (ALEJANDRO et al., 2012).

Como metodología, la EP retoma a la sistematización como forma particular de investigar y que comparte sus compromisos en torno a la transformación social (...) "es un 
proceso que parte de la práctica, reflexiona la práctica y produce saber para transformar la práctica" (MESSINA, 2005, p.163).

También es una metodología que procura despertar la iniciativa, el sentido crítico y la creatividad, tratando de que los sujetos sean protagonistas de la interacción educativa. Así, la educación popular tiene proyecciones éticas, políticas y culturales. (GRACIA, 2013).

Entretanto, se puede afirmar que apunta a la construcción de un nuevo paradigma educacional, que se opone a un modelo de educación autoritaria, de reproducción, predominantemente escolarizado y que disocia la teoría de la práctica. De ahí la propuesta de una educación problematizadora, dialógica y horizontal, que desarrolla el pensamiento crítico, la ecología de saberes y la vocación por la humanización. (JARA, 2018).

La EP es una pedagogía que se realiza desde el protagonismo de las personas, grupos, organizaciones populares en los distintos ámbitos de la sociedad. Abarca también, a quienes sufren otros tipos de opresiones, producto del racismo, colonialismo, patriarcado, violencia de género, sexo, entre otros. Sus contenidos, métodos, propuestas, no se deciden por fuera del grupo social que forma parte del proceso, sino que se va realizando junto y como decisión del grupo. Es una pedagogía de los sujetos organizados, o que tienden a organizarse para luchar contra la opresión. (ALEJANDRO et al., 2013).

Es una pedagogía de la pregunta que requiere que los educadores y educandos que participan partan de una realidad cognoscente para y desde ella, poder transformarla. Es una práctica educativa que reconoce lo que educandos y educadores saben sobre determinado tema para construir y generar nuevos saberes.

En su contribución a la educación ciudadana se ha reflexionado como una pedagogía de lo público, en tal sentido el Consejo de Educación de Adultos de América Latina (CEAAL), (1994, p.73, apud PONTUAL, 2006, p.92) define:

La EP constituye una práctica referida al hacer y al saber de las organizaciones populares, que busca fortalecerlas en cuanto a los sujetos colectivos, y así, contribuir a través de su acción-reflexión al necesario fortalecimiento de la sociedad civil y de las transformaciones requeridas, tanto para la construcción democrática de nuestros países, como para el desenvolvimiento económico con justicia social. 
Castillo y Osorio (1997, p. 42-43 apud PONTUAL, 2006, p.93) por su parte expresaron:

La EP es una pedagogía de lo público, de la decisión, de la construcción de un sentido común. La EP es ella misma una educación ciudadana, una esfera pública. Al hablarnos de EP nos referimos a la creación en distintos ámbitos (escuelas, barrios, movimientos sociales, familias) de esferas públicas que permitan que las personas se reúnan en lugares diversos para hablar, intercambiar información, escuchar, hacer negociaciones. Al referirse a las principales concepciones de educación ciudadana y sus formulaciones pedagógicas, afirman que el punto central es constituir una pedagogía que suscite la necesidad de pensar en nuevos horizontes y orientaciones para la práctica educativa en todos los espacios sociales.

En tal sentido, Pontual (2006, p.94) advierte:

[...] la necesidad de una acción educativa planeada y de la creación del instrumental pedagógico capaz de propiciar cualidad sustantivamente democrática a la intervención de los diversos actores en los espacios públicos y canales de participación ciudadana. [...] En este contexto, se puede afirmar que las diversas prácticas participativas que se desarrollan en la perspectiva de democratización de los espacios públicos se vienen constituyendo en cuantos procesos educativos y que vienen proporcionando importantes aprendizajes para los actores de la sociedad y de los gobiernos. [...]

Por tanto, la apertura de nuevas formas y canales de participación requiere una práctica pedagógica planeada, capaz de orientar el necesario proceso de cambio de actitudes, valores, mentalidades, comportamientos, procedimientos, por parte de toda la población.

La EP, en sus críticas a la educación tradicional, desde sus inicios genera vías metodológicas consecuentes con el tipo de valores, relaciones sociales y proyectos de futuro a construir. Por lo que el desarrollar metodologías coherentes con sus principios emancipadores, ha estado presente en la creación de criterios educativos tales como la construcción colectiva de conocimientos, el diálogo, el partir de la realidad de los educandos, la participación y articulación de la teoría con la práctica.(TORRES, 2016).

La investigación pedagógica en torno a la EP como propuesta educativa, constituye un área en la que es necesario continuar reflexionando, en tal sentido: 
Sus avances cuestionan las prácticas de concientización o transmisión ideológica que aún subsisten en algunas experiencias educativas. Así mismo se ha reconocido la amplitud del mundo interno de los sujetos donde la razón es un componente tan importante como los sentimientos, la voluntad, los miedos, las simpatías y odios (TORRES, 2016, pág.50)

\section{Dimensiones ética y política de la EP a tener en cuenta en la práctica pedagógica}

\section{Dimensión ética}

Nuñez (1997, apud Torres, 2016, p.51) apunta que "la EP más que un conjunto de ideas, es una actitud ética lo que implica tomar en cuenta la educación en valores y para ello reivindicar la educación para la vida, para el amor, la justicia y la solidaridad entre los hombres".

Freire apunta que la ética ante la vida debe estar sustentada en valores y principios que sitúen a los seres humanos como centro y fin de la actividad social. Es decir, una ética contrapuesta al capitalismo y su ética funcional, pragmática, discriminatoria y excluyente de grandes grupos humanos que "no compiten" en esa sociedad, pues se les han negado los derechos fundamentales a la vida. (FREIRE, 2013).

En el evento internacional Universidad 2014, en la Habana, Frei Betto (2014), en la conferencia magistral impartida en su frase de conquistar la ética de la política, expresa que significa, “evitar caer en tentación en cuanto a la falta de ética” y además agrega:

Es necesario significar que uno de los grandes errores del socialismo europeo radica en haber creído o pensado en que todos los hombres nacidos en una sociedad socialista, son socialistas por naturaleza, como si las concepciones, ideologías y valores fueran transmitidos genéticamente. Se olvidaron pues de la concepción marxista que el hombre piensa como vive es decir que la conciencia refleja las condiciones materiales de existencia, pero también influye sobre ella y las transforma. Es decir que existe una interacción dialéctica entre el sujeto y la realidad en la que vive. (p.4).

Más adelante el mismo autor expresa que: 
Es conveniente retomar a Lenin cuando dijo que el amor es un producto cultural, esto se logra mediante prácticas pedagógicas que fomentan valores altruistas, gestos solidarios, ideales colectivos, entre otros. $Y$ ese es precisamente el papel del educador en la formación política del educando, no limitarse a transmitir conocimientos y a facilitar el acceso al patrimonio cultural de la humanidad y de la nación sino también suscitar en el educando el espíritu y la militancia revolucionaria en todos los sentidos. Luchar contra la corrupción que es una mala yerba inherente al capitalismo y al socialismo y ante la cual hay una tendencia a la vulnerabilidad cuando se trata de renunciar al prestigio, poder y dinero. Por tanto el papel del educador, debe no solo formar para una posible ubicación en el mercado laboral sino formar seres humanos dignos, felices, dotados de conciencia crítica para perfeccionar el contexto social en el que se inserta y convertirse en un sujeto histórico-transformador de la realidad que vive. (BETTO, 2014, p.5)

\section{Dimensión política}

Freire (2013), al hablar de la naturaleza política de la educación puntualiza que su fin es la emancipación humana, la reinvención del poder a partir del sueño de que es posible una nueva sociedad sin oprimidos ni opresores. Es en función de ello que promueve el desarrollo reflexivo y crítico de los hombres y mujeres en los procesos de liberación, construcción y constitución de sus realidades sociales cotidianas. Por lo que se promueve la acción transformadora de los cambios sociales.

De ahí que: ¿cuál es el papel de los docentes en la formación de la conciencia en las nuevas generaciones?; ¿cómo se contribuye a esa educación emancipadora y descolonizada?; ¿cómo se forman sujetos críticos, dispuestos a transformar la realidad imperante?

Por tanto, tener en cuenta estas dimensiones en prácticas pedagógicas universitarias desde esta perspectiva educativa, constituye un desafío al intentar superar el epistemicidio que surge en la universidad, porque se elimina el saber popular de la producción científica que esta institución genera. (SOUSA SANTOS, 2010)

Para alcanzar tales propósitos es necesario evitar o erradicar los síntomas de la educación bancaria. Por lo que desde la EP como concepción político-pedagógica, se defienden postulados y principios develados en el pensamiento y la obra freireana a saber: necesidad de promover una concepción humanista del mundo, en la que los seres 
humanos sean sujetos protagonistas de la historia, y no meros objetos. Esto presupone un enfoque holístico de la realidad en sus múltiples dimensiones: culturales, sociales, psicológicas, históricas, antropológicas. Refiere también el carácter cambiante e inacabado de la realidad social: sujeta siempre a transformaciones para mejorarla. Pondera la importancia del diálogo, como vía en la construcción y deconstrucción colectiva en la que resulta fundamental la pregunta, la problematización, el debate fraterno, el aporte de todos para el desarrollo de las capacidades de autotransformación de los sujetos para los cambios sociales, no restringida al ámbito escolar, sino extendida al conjunto de la sociedad. Destaca la comunicación horizontal en el proceso de aprendizaje: que se expresa en la superación de la contradicción entre educadores y educandos, sin que por ello se diluya el rol del educador, que sin duda tiene un saber científico que aportar y dispone de un arsenal metodológico para facilitar el proceso de conocimiento. Expresa la necesidad de aplicar vías de trabajo que propicien el respeto a las diferencias, el intercambio y diálogo de saberes que dé cuenta de la valoración positiva de la riqueza de lo diverso y se pronuncie por un mundo en el que quepan otros mundos, que no sea excluyente y permita establecer sueños y utopías. Significa la concientización como capacidad de identificar las causas y consecuencias de nuestra posición y la de los demás en el conjunto de las relaciones sociales, de desenmascarar los mitos que justifican la dominación y ocultan las diferencias entre lo natural y lo que puede cambiar, de proponer alternativas desde la perspectiva de la liberación. (ALEJANDRO, et.al., 2012).

En tal sentido insiste en que la verdadera educación es la que concientiza al educando sobre las contradicciones del mundo humano. Estas contradicciones, una vez concientizadas, inquietan al educando a reflexionar y accionar para la transformación de la realidad. (FREIRE, 1970). 


\section{Contribución de la EP a los procesos formativos universitarios. Ejemplos de prácticas pedagógicas en cursos de postgraduación en la Universidad de Camagüey, Cuba y Universidad Federal de Minas Gerais, Brasil}

Los presupuestos teóricos anteriores se constituyen en base para continuar impregnando a los procesos formativos de una perspectiva diferente, que como proceso pedagógico permita la construcción de una comunidad de aprendizaje, que no se limita al qué y el cómo del proceso educativo sino también el a quién y para qué, de manera que los que participan se conviertan en sujetos críticos del proceso de formación y, conscientes de transformar prácticas sociales excluyentes y discriminatorias, asimismo cada vez más democráticas y descolonizadoras.

$\mathrm{Al}$ respecto, es ineludible retomar lo expresado por el sociólogo norteamericano, Henry Giroux (2008), representante de la Pedagogía critica, al expresar que la universidad debe convertirse en un lugar de enseñanza crítico y lleno de vida, reconociendo que se vive en un tiempo, que necesita de pensamiento crítico, diálogo informado y responsabilidad rigurosa. Es necesario ver a la pedagogía como frontera que permita a los estudiantes analizar, desde el punto de vista ético y político, el vínculo entrelazado de la experiencia y del pensamiento, de la teoría y de la práctica, de las ideas y de la vida pública.

Por tanto, la EP como movimiento pedagógico, cultural, ético y político, supone la constitución del sujeto popular en sujeto de saber y poder. Por ello apuesta a la emancipación, la iniciativa y creatividad intelectual y al desarrollo de su poder. Pero de un poder cualitativamente diferente basado en el servicio, la solidaridad, la justicia social, la responsabilidad, el compromiso, el desarrollo de capacidades, acompañado de una ética que opere en forma contrahegemónica a la dominación. (ALEJANDRO et al., 2013).

Por eso, el diálogo y la participación son indispensables para la emergencia de ese nuevo sujeto popular. Se trata, de que todas las personas estén en posibilidad de proponer y 
crear un diálogo impregnado de humildad, esperanza, amor y pensar crítico, y entendido como praxis en y con el mundo, para transformarlo.

Por otro lado, el investigador portugués Sousa Santos (2008), explica que la ecología de saberes, como profundización de la investigación-acción, propicia un conjunto de prácticas que promueven una nueva convivencia activa de saberes con el supuesto de que todos ellos, incluido el saber científico, se pueden enriquecer en ese diálogo. Es una forma de extensión en sentido contrario, desde afuera de la universidad hacia dentro de la universidad. Consiste en la promoción de diálogos entre el saber científico y humanístico que la universidad produce y los saberes populares, tradicionales, urbanos, entre otros, que circulan en la sociedad.

Un aspecto esclarecedor sobre este particular parafraseando a Freire, cuando dice que en la medida que el hombre integrándose a las relaciones de su contexto de vida reflexiona sobre ellas y aporta respuestas a los desafíos que le plantean, el hombre crea cultura.

$\mathrm{Al}$ analizar el carácter interactivo de la educación con la sociedad expresa:

[...] solamente los seres que históricamente se tornaron capaces de aprender y de saber, fueron capaces al mismo tiempo, de intervenir en una realidad que los condiciona. La educación, [...] asume un papel de importancia fundamental. [...] la educación viabiliza la intervención. [...] la educación sola no hace. Pero puede lograr algunas cosas importantes, entre ellas permite abrir caminos e intervenir en el mundo. (FREIRE, 1997, p.10)

Por lo tanto, desde la perspectiva planteada, hay que lograr que los procesos formativos permitan un crecimiento humano en lo cultural y educativo de cada uno de los sujetos que participan, de manera tal que los hábitos, intereses, modos de pensar y sentir, la manera en que las personas proyectan su futuro así como las necesidades educativas y culturales puedan contribuir a elevar la espiritualidad, como indicador de calidad de vida de la población.

Antes de ejemplificar las prácticas pedagógicas universitarias, es significativo referir al autor y estudioso del tema de la EP en Brasil cuando pregunta:

¿El lugar de la EP debería ser, situarse vocacionalmente como alternativa de modalidades de acción cultural por opción al margen o, en zonas de fronteras frente a universidades? 0 
si ¿la EP debería venir a conquistar lugares de justa presencia e influencia en el interior de las universidades y más aún en las facultades de educación? (BRANDAO, 2013, p. 23).

En tal sentido, si bien estas preguntas pudieran no tener las respuestas acertadas en el contexto educativo universitario actual, al menos el presente artículo, intenta construir una propuesta, que contribuye a develar de manera crítica destinos educativos y culturales emancipadores en los sujetos que participan.

\section{Cursos de postgraduación de la disciplina Paulo Freire en la Universidad Federal de Minas Gerais}

El curso de imparte desde el 2005 hasta la actualidad, en la Facultad de Educación, tiene años en que se oferta en cada semestre y otros, una vez. Se realiza con la coordinación de dos o tres profesores. Participan estudiantes de postgraduación de diversas áreas de las ciencias humanas, sociales, de la salud, naturales y exactas, entre otras.

La metodología empleada propicia la presentación y conocimiento entre los integrantes del grupo y convoca al debate, defensa, y selección del libro y lecturas que serán estudiadas en el curso a partir de las propuestas de los participantes. Para lo cual se emplean técnicas de participación grupal que propician el cumplimiento metodológico del objetivo general de la disciplina.

Una vez seleccionados libro o libros y lecturas se distribuyen los roles entre los integrantes para conducir el debate de cada capítulo o parte de los textos. De manera que este es conducido en cada encuentro por los participantes del curso y dirigido por los profesores de la disciplina.

Para el debate de cada parte, se emplean materiales didácticos diferentes, seleccionados por los responsables del tema. Entre ellos se destacan los productos culturales como audiovisuales, música y poemas. También, la presentación de entrevistas y las lecturas comentadas. 
El empleo de técnicas de participación grupal facilita la devolución de los textos leídos individualmente y el aporte al grupo a partir de la contextualización y actualidad de los contenidos correspondientes. Por tanto, permiten el vínculo de los temas analizados con la realidad histórica, política y cultural que vive la sociedad brasileña y la crítica consecuente a hechos y situaciones que se presentan.

El curso sigue una dinámica de relatoría, que lo distingue por su carácter creativo, diverso, movilizador y místico. Esta consiste en recoger lo acontecido en cada encuentro y relatar de diferentes maneras, en el encuentro siguiente, lo vivido durante el proceso de construcción colectiva. Contribuye por tanto, a dejar constancia de la memoria de la disciplina, a la integración grupal y el compromiso individual. Además, permite de una forma consciente la exposición y manifestación sentida de emociones, sentimientos y valores emancipadores en correspondencia a la necesidad de justicia y transformación social.

Es importante significar que esta relatoría como aspecto metodológico del curso, tiene sus antecedentes en otras realizadas en ediciones anteriores de esta misma disciplina y en la de Formación de educadores de jóvenes y adultos en el curso de Pedagogía. De lo que se derivó una publicación, al respecto, como bien expresan sus autores "más que recordación, constituye un instrumento de trabajo en la formación del educador de jóvenes y adultos." (SOARES; SILVA, 2009, p. 221).

El artículo referido a las memorias en formas de relato escrito por los autores mencionados aporta la lógica a seguir en las ediciones posteriores de las disciplinas referidas como una práctica pedagógica necesaria que constituye "un instrumento de análisis, de observación, de creatividad y sobretodo de aprehensión de un evento de aprendizaje." (SOARES; SILVA, 2009, p.222).

También es importante destacar que los antecedentes de esta práctica pedagógica advierten la necesidad de dejar constancia de informaciones, discusiones, referencias y vivencias en la sala de aula durante el transcurso de la disciplina, que es importante rescatar y luego recordar para el ejercicio de la docencia y, por tanto, evitar que se pierda esa valiosa contribución de los estudiantes en colaboración con los profesores. 
Por otra parte, el artículo que recoge las memorias en forma de relato precisa varios aspectos que sirven de guía para la acción del profesor y por tanto evalúan el alcance pedagógico. Se puntualiza pasar de la memoria al registro: por el significado que el aula pasa a tener cuando se torna objeto de aprehensión y registro y en cierta medida, sugiere un compromiso mayor de alumnos/as. Además porque la narrativa manuscrita exige una serie de habilidades que es necesario desarrollar. Se significa el relato como vía metodológica que permite recuperar la experiencia a la luz de la mirada del observador. La contribución de los relatos para ser sujetos de lo que se vive en la sala de aula a partir de los saberes construidos y la construcción de un mundo mejor. Finalmente, los autores puntualizan que lo descubierto a través de los relatos contribuye de manera significativa a la construcción de una secuencia de discusiones y temáticas, por parte de los alumnos/as de acuerdo a sus intereses. Asimismo la presencia de subjetividades en el discurso indirecto y libre que facilita un espacio de libertad y autonomía para el ejercicio de la creación. (SOARES; SILVA, 2009).

Todo lo anterior ha servido para el perfeccionamiento del proceso de recolección de información y de conformación de las memorias escritas posteriores, en el curso ejemplificado de la disciplina de la postgraduación. La misma, por el alcance que se logra en los debates en la sala de aula, constituye una práctica que favorece el crecimiento de los sujetos, el intercambio y dialogo de saberes y, a partir de esto, la reconstrucción de ideas, conceptos, miradas, manifestaciones, relaciones de poder, hechos, comportamientos, críticas y cuestionamientos que ponen al descubierto prácticas naturalizadas de pensamiento colonizado y reproductor de la cultura dominadora. Por tanto, contribuyen a la reinvención del pensamiento de Freire y a su constante actualidad y contextualización.

La evaluación final consiste en redactar por cada participante el significado que ha tenido lo temático y lo dinámico del proceso vivido durante el transcurso de la disciplina, asimismo los aprendizajes alcanzados desde la perspectiva freireana en aras de la transformación social y los aportes de la disciplina en el orden teórico-metodológico a los diferentes proyectos de pesquisa de los estudiantes de la postgraduación. 


\section{Curso de formación en Educación Popular, impartido en la Universidad de Camagüey, (UC) Cuba}

En Facultad de Ciencias Sociales de la UC, se desarrolla hace más de cinco años un curso denominado Teoría y Práctica de la Educación Popular, que se imparte en programas de graduación y postgraduación en el que participan estudiantes y profesores de diferentes niveles educativos, perfiles, regiones y países, de otras universidades, miembros de instituciones, asociaciones, organizaciones, movimientos sociales y líderes comunitarios. Todos de diferentes perfiles de formación, orígenes socioculturales, relación laboral, grupo etario, intereses, entre otras variables.

En la impartición del curso constituyen principios a tener en cuenta, partir de la práctica, teorizar desde la práctica y retornar a la práctica transformada, a partir de los profundos cambios que tienen lugar en la universidad cubana, entre ellos la aparición de nuevos actores, la reinserción en el contexto educativo de personas provenientes de diferentes sectores laborales, un claustro profesoral con variada formación académica y cultural, las diferentes culturas que confluyen en el espacio universitario, la confluencia intergeneracional con diversos modos de comprender el mundo, estilos de vida, costumbres, medio sociocultural del que proceden, modos de vestir, normas de convivencia social y colectivas, códigos sociolingüísticos que establecen, gustos, intereses, creencias, metas y proyectos de vida.

Como proceso toma en cuenta los postulados de Freire y los aplica en una práctica pedagógica democratizadora, a diferencia de la educación bancaria. El curso es impartido por un equipo de profesores coordinadores (no menos de tres y no más de cinco), formados en EP.

Antes de iniciarse se aplica una encuesta a los matriculados para conocer intereses, procedencias socioculturales, ocupación, formación, experiencias de trabajo y expectativas con el curso. Esto ayuda al equipo de coordinación, a tener un diagnóstico inicial de las personas matriculadas y por tanto a conocer la diversidad del grupo. 
El curso se inicia con una técnica de presentación, luego se levantan expectativas y se realiza un diagnóstico grupal. Se distribuyen los roles y se toman los acuerdos del grupo, se introduce el curso, en el que se precisan objetivos y metodología a seguir durante todos los encuentros. Se comparten los roles del grupo, previo interés, afinidad, gusto... de los participantes y se organizan en comisiones de mística, comunicación, evaluación, relatoría y logística.

Los acuerdos del grupo se enriquecen en la medida que el curso avanza y va creciendo el grupo del yo, al nosotros. Esto facilita el clima de aprendizaje y el sentirse a plenitud para expresar lo que piensan y sienten.

Se trabajan contenidos sobre fundamentos teóricos y metodológicos de la EP, orígenes y desafíos así como la identidad como categoría sociopsicológica. Los contenidos se articulan con lo metodológico, lo grupal, lo individual, la proyección al nosotros en función de las metas comunes.

Metodológicamente se desarrolla una lógica inductiva: el grupo, a partir del análisis de prácticas concretas cotidianas, tiene que llegar a análisis más generales de la sociedad, de los procesos que en ella tienen lugar.

Otras lógicas que se siguen consisten en: ir del aporte individual al grupal, y de ahí al plenario. Así como también ir de lo más cercano y conocido por los participantes, a lo que más desconocen; de lo sencillo a lo complejo.

En el primer encuentro se levantan las prácticas externas e internas de los participantes, referidas a la presencia de la cultura de la dominación y las relaciones de poder en diferentes espacios sociales. A través de técnicas que propician el desmontaje de dichas prácticas. Esto facilita el desarrollo durante todo el proceso del curso.

La metodología participativa ayuda a lograr debates desde los textos, en diálogo con el contexto y las vivencias de los participantes. Se insiste en no reproducir el contenido de los textos, si no conversar y reinventarlos. De manera que la devolución pone a prueba la creatividad del grupo y a cada uno de los integrantes. Cada sesión de encuentro se inicia con una mística que vincule con lo temático y que permita que afloren los sentimientos y emociones de los participantes, creando un buen clima para el debate. 
Las comisiones de trabajo que se constituyen son las encargadas de escribir la relatoría de los encuentros correspondientes y presentarse en cada uno, en vínculo con los acontecimientos del contexto.

Es decir, la metodología empleada tiene en cuenta:

- Partir de la práctica, teorizar sobre la práctica y regresar a la práctica enriquecida.

- Se aplica el triple diagnóstico: teniendo en cuenta el contenido a tratar: qué se entiende o se sabe, qué se hace y qué se siente sobre determinado contenido.

- La incorporación de lo lúdico en dependencia de las características de los participantes.

- La presencia de lo místico, como aspecto que contribuye a que afloren sentimientos, emociones, motivaciones, necesidades.

- Aplica una lógica de aprendizaje dialéctica.

- Utiliza recursos didácticos tales como: música, materiales audiovisuales, plumones, papelógrafos, filmes, libros, revistas, materiales digitales.

Se realiza una recuperación metodológica en los últimos encuentros acerca de todo lo acontecido en el curso, tanto de lo temático como de lo dinámico, lo cual facilita la relatoría final. Se van realizando evaluaciones parciales a través de técnicas que evalúan contenido, cumplimiento de objetivos, coordinación del curso, proceso grupal e individual vivido, entre otros aspectos.

La evaluación final, se realiza en subgrupos, consiste en presentar un diseño de una propuesta de trabajo social concreto, en dependencia de las características y objetivos de los participantes, en el que se tome en cuenta lo temático y lo dinámico del curso a la hora de su posible aplicación práctica.

La evaluación se entiende como un proceso de reflexión colectiva que tiene como finalidad acompañar el desarrollo de la práctica para conocerla, valorarla y corregir sus rumbos en función de los objetivos. Así concebida, es un hecho educativo. Mediante esta no se juzga a las personas; se analizan los procesos que se dan en los grupos. Es eminentemente participativa. A partir de sus resultados, el grupo analiza y decide cuáles 
y cómo deben ser las acciones futuras sobre la base de las experiencias que se viven durante el proceso. Esta evaluación permite la identificación y análisis de los errores también se constituye en fuente de aprendizaje, tanto para los que participan como para los que coordinan.

Se hace una relatoría final que recorre todo lo acontecido durante el curso, esta se realiza en dependencia de la creatividad de los responsables.

Es importante aclarar que durante todo el proceso formativo, la comisión de observación es la encargada de apuntar aspectos que contribuyen a estimular el crecimiento grupal e individual así como lo que puede estar entorpeciendo.

En sentido general una característica insoslayable que distingue al curso es que este propicia un buen clima grupal para favorecer el aprendizaje.

Por lo tanto es necesario la no manipulación de las personas que participan de los procesos. Es decir:

- Tomar en cuenta sus expectativas e intereses.

- Trabajar educativamente las necesidades sentidas por las personas participantes, para que se conviertan en necesidades más estratégicas, de crecimiento y superación.

- Darles participación en la toma de decisiones.

- No imponerles soluciones que realmente no han sido propuestas por esas personas.

- Cumplir los acuerdos del grupo tanto para los participantes como para los que coordinan.

- Sentarnos en círculo no indica que estamos ante una práctica de educación popular.

Si no se intenciona que las personas analicen y reflexionen sobre su realidad, no se producirán transformaciones en el sentido emancipatorio que se proponen desde la educación popular. 
Una vez concluido el curso, se definen las continuidades de los participantes en su formación en EP según sus intereses y se les oferta las otras temáticas a trabajar desde esta perspectiva metodológica: Género, Trabajo Comunitario, Relaciones étnico/raciales, Comunicación popular, Trabajo grupal y coordinación de grupos y Ecología política.

Como parte de las continuidades también se solicita a los participantes, la incorporación o no a la Red de EP o a la Red Fe por Cuba, en dependencia de sus necesidades y objetivos de vida, laboral o profesional. Redes que agrupan a parte de la sociedad civil cubana en defensa del modelo social que se construye y que constituye una práctica de gestión extensionista desde algunas universidades.

\section{Consideraciones finales}

Los fundamentos, principios, dimensiones y contribuciones de la EP exigen continuar sistematizando el cuerpo de categorías que la conforman en aras de develar su utilidad en el diseño e implementación de propuestas pedagógico-didácticas democratizadoras. La EP como concepción educativa y variante de la Investigación Acción Participación, constituye una propuesta política, social, pedagógica y metodológica que requiere ser tomada en cuenta para perfeccionar los diferentes procesos formativos en la Educación Superior. Esta concepción educativa permite la realización de acciones que involucran y comprometen a los sujetos de diferentes contextos a partir del diálogo entre los saberes académicos y los saberes populares. Los resultados de los ejemplos mostrados evidencian cuánto se puede alcanzar en la formación política, cultural y pedagógica de docentes y estudiantes universitarios desde una perspectiva que problematiza, con visiones emancipadoras, formas tradicionales de enseñar y aprender. Estas prácticas ejemplificadas ilustran que aún con aciertos y desaciertos posibles, en los casos cubano y brasileño, la propuesta de EP de Freire debe ser más debatida y reinventada en los espacios académicos, de manera que se logre articular la educación y la cultura en función de la transformación crítica de realidades sociales en general. 


\section{Referencias}

ALEJANDRO, M. et al. Concepción y metodología de la Educación Popular. Selección de lecturas. Tomo I. La Habana: Ed. Caminos, 2013.

ALEJANDRO, M. et al. Formación en Educación Popular Acompañada a Distancia. (FEPAD). Concepcióny metodología de la educación popular: Guía para coordinadoras y coordinadores de grupo. La Habana: Ed. Caminos, 2012.

BETTO, F. América Latina amenazada con retroceder. América Latina en Movimiento, Quito, año 42, n. 533, p. 7-9, jun. 2018. Disponible en: < http//www.alainet.org/revista/phtml $>$ Acceso el 5 de agosto 2019, 16:53.

BETTO, F. Conferencia especial en Congreso Internacional Universidad, La Habana, Cuba. 2014.

BRANDAO, C. Educación Popular antes y ahora. Revista del Centro de Educación y Letras de la UNIOESTE, v. 15, n. 1, p. 10-24, 1 sem. 2013.

BRANDAO, C. Educación Popular antes y ahora. Recuerdos de ayer, preguntas para ahora. Revista de la IICE, v. 32, 2012.

FREIRE, P. Paulo Freire: constructor de sueños. En: ALEJANDRO, M. et al. Concepción y metodología de la Educación Popular. Selección de lecturas. Tomo I. La Habana: Ed. Caminos, 2013. p. 243-250.

FREIRE, P. Las perspectivas de la educación. Último reportaje, concedido el 16 de abril a la periodista israelí Ethan Bronstein. Jornal Folba de Sao Paulo, Sección 3, p. 10, 4 mayo 1997.

FREIRE, P. La educación como práctica de la libertad. 17. ed. Brasil. Ed. Paz e Terra, 1986.

FREIRE, P. Pedagogía del oprimido. Buenos Aires: Ed. Siglo XXI, 1970.

FREIRE, P. Pedagogía de la esperanza. Rio de Janeiro, Brasil: Ed. Paz e Terra, 1968.

GIROUX, H. La universidad secuestrada. Caracas: Ed. Río Orituco, 2008.

GRACIA, M. Rol de la educación en la hegemonía del bloque popular. En: ALEJANDRO, M. et al. Concepción y metodología de la Educación Popular. Selección de lecturas. Tomo I. La Habana: Ed. Caminos, 2013. p. 67-72.

JARA, O. ¿Qué democracia tenemos y qué democracia queremos? América Latina en Movimiento, Quito, año 42, n. 533, jun. 2018. p. 3-6. Disponible en: http//www.alainet.org/revista/phtml Acceso el 5 ago. 2019.

JARA, O. Resignifiquemos las propuestas y prácticas de EP por delante de los desafíos históricos contemporáneos En: PONTUAL, P. (Org.). Educación Popular en América Latina: diálogos y perspectivas. [S.l.]: CEAAL; MEC/UNESCO, 2005.

MEJÏAS, M. La educación popular en el siglo XXI. Una resistencia intercultural desde el sur y desde abajo. Praxis \& Saber, v. 6, n. 12, p. 97-128, jul/dic. 2015. 
MEJÏAS, M. Educaciones y pedagogías críticas desde el sur (cartografias de la educación popular). Lima: CEAAL, 2011.

MEJÏAS, M.; AWWAD, I. La educación popular boy en tiempos de globalización. Bogotá: Ed. Aurora, 2007.

MESSINA, G. La sistematización: acerca de su especificidad. Revista Interamericana de Educación de Adultos, v. 27, n. 2, jul./dic. 2005.

NUÑEZ, C. Educar para transformar, transformar para educar. En: ALEJANDRO, M. et al. Concepción y metodología de la Educación Popular. Selección de lecturas. Tomo I. La Habana: Ed. Caminos, 2013. p. $264-268$.

PONTUAL, P. Educación Popular y democratización de las estructuras políticas y espacios públicos. En: PONTUAL, P.; IRELAND, T. Educación Popular en América Latina: diálogos y perspectivas. Electrónica. Brasilia: MEC/UNESCO, 2006. p. 91-101.

ROMERO, M. I. Orígenes de la Educación Popular en América Latina. In: ALEJANDRO, M. et al. Concepción y metodología de la Educación Popular. Selección de lecturas. Tomo I. La Habana: Ed. Caminos, 2013. p. 229-241.

SOARES, L.; SILVA, F. Memoria en forma de relatos de aula. Más que recordación, un instrumento de trabajo en la formación del educador de jóvenes y adultos. En: NARCIZO, M.; SOUZA, R. Prácticas de educación de Jóvenes y Adultos: complejidades, desafíos y propuestas. Belo Horizonte: Autêntica, 2009. p. 221-222.

SOUSA SANTOS, B. Para descolonizar Occidente: Más allá del pensamiento abismal. Buenos Aires: CLACSO; Prometeo Libros, 2010.

SOUSA SANTOS, B. La universidad en el siglo XXI: para una reforma democrática y emancipadora de la universidad. [S.1.]: Centro Internacional de Miranda, Colección de Educación Superior, 2008.

SOUZA, J. F. La vigencia de la Educación Popular. En: PONTUAL, P. (Org.). Educación Popular en América Latina: diálogos y perspectivas. [S.1.]: CEAAL; MEC/UNESCO, 2005.

TORRES, A. La educación popular. Trayectoria y actualidad. 2. ed. Bogotá: El Búho, 2016.

VALDÉS, R. Diccionario del Pensamiento Martiano. La Habana: Ciencias Sociales, 2007.

RECIBIDO: $26 / 02 / 2020$

APROBADO: $11 / 05 / 2020$

RECEBIDO: $26 / 02 / 2020$

APROVADO: $11 / 05 / 2020$

RECEIVED: 02/26/2020

APPROVED: 05/11/2020 